\title{
Analisis Pengaruh IHSG, Inflasi, BI Rate dan Nilai Tukar Rupiah terhadap Fluktuasi Harga Saham Bank Di Indonesia Menggunakan Metode Regresi Linear Berganda
}

\author{
Yeremia Herry Parulian, Betty Subartini, Riaman \\ Jurusan Matematika FMIPA Universitas Padjadjaran \\ Jl. Raya Bandung-Sumedang km 21 Jatinangor Sumedang 45363 \\ e-mail : yeremiaherry@ymail.com, bettysubartini@yahoo.com, \\ riaman_02@yahoo.co.id
}

\begin{abstract}
ABSTRAK
Harga saham merupakan sebuah acuan dalam mengambil suatu keputusan khususnya dalam trading di pasar modal. Dalam trading tersebut, investor dapat melihat harga saham untuk menentukan seberapa besar investasi yang akan ditaruh. Pada paper ini akan dianalisis harga-harga saham yang ada di Bursa Efek Indonesia (BEI) yang dikhususkan untuk lima bank di Indonesia yang sahamnya diperjualbelikan (Tbk), bank-bank tersebut diantaranya Bank BCA (BBCA), Bank Rakyat Indonesia (BBRI), Bank Negara Indonesia (BBNI), Bank Mandiri (BMRI), dan Bank CIMB Niaga (BNGA). Faktor yang mempengaruhi harga saham yaitu IHSG (Indeks Harga Saham Gabungan), nilai tukar rupiah, inflasi serta BI rate. Pada hasilnya dapat dilihat model regresi linearnya dan pengaruh faktor-faktor tersebut terhadap harga saham, dalam penganalisisannya model regresi diubah ke dalam model regresi yang di-difference-kan agar bersifat BLUE (Best Linear Unbiased Estimator). Setelah dianalisis, model yang terbaik adalah saham Bank dengan semua variabel bebas berpengaruh signifikan terhadap saham Bank Mandiri secara serempak, dan hanya IHSG yang mempengaruhi secara parsialnya.

Kata kunci: Harga saham, Investor, Regresi Linier, IHSG, Inflasi, Nilai Tukar, BI Rate dan Difference
\end{abstract}

\begin{abstract}
The stock price is a benchmark in making a decision, especially in trading in the stock market. In such trading, investors can see the stock price to determine how much investment will be placed. In this paper will be analyzed the prices of existing shares in the Indonesian Stock Exchange (BEI) is devoted to the five banks whose shares are traded in Indonesia (Tbk.), these banks include Bank BCA (BBCA), Bank Rakyat Indonesia (BBRI), Bank Negara Indonesia (BBNI), Bank Mandiri (BMRI), and Bank CIMB Niaga (BNGA). Global factors that affect stock prices are JCI ( Composite Index), exchange rate, inflation and the BI rate. Results can be seen on the linear regression model and the influence of these factors on stock prices, the regression model in this analyze converted into a
\end{abstract}


regression model that in difference to makes a BLUE's (Best Linear Unbiased Estimator ) model. Once analyzed, the best model is the Bank Mandiri, With all the independent variables significantly influence the bank stocks simultaneously, and only JCI influence in partial.

Keywords: Stock Price, Investors, Linear Regression, JCI, Inflation, Exchange Rate, Bank Rate and Difference.

\section{Pendahuluan}

Perkembangan ekonomi suatu Negara dapat diukur dengan banyak cara, salah satunya dengan mengetahui tingkat perkembangan dunia pasar modal dan industri-industri sekuritas pada negara tersebut. Bidang perekonomian yang cukup berkembang pada saat ini adalah bank, khususnya di Indonesia. Menurut Undang-undang Negara Republik Indonesia Nomor 10 Tahun 1998 Tanggal 10 November 1998 tentang perbankan, yang dimaksud dengan bank adalah badan usaha yang menghimpun dana dari masyarakat dalam bentuk simpanan dan menyalurkannya kepada masyarakat dalam bentuk kredit dan atau bentuk-bentuk lainnya dalam rangka meningkatkan taraf hidup rakyat banyak. Sekarang ini bank tidak hanya melakukan aktifitas di intern bank saja seperti simpan-pinjam, kredit usaha, atau Kredit Pemilikan Rumah (KPR). Namun, bank juga beraktifitas dalam dunia pasar modal.

Pasar modal (capital market) merupakan pasar untuk berbagai instrumen keuangan jangka panjang yang bisa diperjualbelikan, baik dalam bentuk utang atau pun modal sendiri [1]. Pasar modal yang dalam arti sempit adalah suatu tempat dalam pengertian fisik yang mengorganisasikan transaksi penjualan efek atau disebut sebagai bursa efek

Keikutsertaan bank di Indonesia dalam pasar modal atau bursa efek ini juga bertujuan agar bank dapat mempunyai dukungan financial dan fundamental di mana itu penting untuk keberlangsungan bank itu sendiri. Pasar modal merupakan sebuah investasi, investasi yang sangat menarik perhatian para investor. Investasi adalah penanaman modal untuk satu atau lebih aktiva yang dimiliki dan biasanya berjangka waktu lama dengan harapan mendapatkan keuntungan di masa-masa yang akan datang [4].Dalam investasi di pasar modal yang perlu diperhatikan adalah mengenai besarnya resiko yang harus ditanggung para investor, oleh karena itu investor harus melakukan halhal yang dapat meminimalkan resiko yang mungkin terjadi, namun tetap menghasilkan keuntungan yang besar juga. Dengan memodelkan data yang ada di trading saham merupakan salah satu contoh yang dapat diambil dalam mempertimbangkan keputusan dengan risiko yang lebih kecil, dengan faktorfaktor seperti fluktuasi IHSG (Indeks Harga Saham Gabungan), inflasi, BI rate, dan nilai tukar dapat menentukan pemodelan saham yang diinginkan karena secara ekonomi faktor-faktor tersebut mempengaruhi fluktuasi saham di pasaran. Tujuan dari paper ini adalah menganalisis apakah saham BBNI, BBRI, BBNI, BMRI, dan BNGA dipengaruhi oleh IHSG, inflasi, BI rate dan nilai tukar, 
serta menentukan saham bank mana yang mempunyai model terbaik sehingga dapat memberi pertimbangkan dalam pengambilan keputusan bagi investor

\section{Metode Penelitian}

Penelitian ini menggunakan desain penelitian analisis deskriptif. Metode analisis deskriptif merupakan metode yang digunakan untuk menganalisis data data yang tersedia dan diolah sehingga diperoleh gambaran yang jelas mengenai fakta-fakta dan hubungan antar fenomena yang diteliti.

Penelitian ini bertujuan untuk menguji pengaruh IHSG, inflasi, BI rate dan nilai tukar terhadap 5 harga saham bank di Indonesia yang terdaftar di Bursa Efek Indonesia dengan data penelitian merupakan data kuantitatif yaitu data yang dalam bentuk angka.

Populasi yang digunakan dalam penelitian ini adalah semua saham yang ada di Bursa Efek Indonesia (BEI) dalam periode 2007-Juli 2013

Kriteria penarikan sampel yang digunakan oleh peneliti adalah sebagai berikut:

1. Bank-bank yang listing di Bursa Efek Indonesia (BEI) selama periode penelitian, yaitu 2007 - Juni 2013.

2. Bank-bank yang cukup dikenal di masyarakat luas sebagai bank yang memiliki reputasi cukup tinggi.

3. Saham Bank yang cukup fluktuatif dalam trading di Bursa Efek Indonesia (BEI).

Berdasarkan karateristik penarikan sampel, maka dipilih sampel penelitian sebanyak 5 Bank.

Penelitian terdahulu dilakukan oleh Siti Rahayu [2] pada penelitian tersebut dibahas pengaruh taksiran kuadrat terkecil dengan error yang berkorelasi serta penyelesaian model regresi linear sederhana menggunakan Metode Durbin Watson dengan menaksir nilai $\rho$ menggunakan statistik Durbin Watson agar model yang didapan merupakan model yang bebas terhadap pengaruh autokorelasi.

Pada penelitian ini digunakan metode analisis regresi dengan difference karena pada penggunaan data saham yang merupakan data time series dalam regresi linear sangat rentan dengan pengaruh autokorelasi, sehingga perubahan model untuk menghilangkan pengaruh autokorelasi perlu dilakukan. Jadi, merumuskan persamaan regresi pada $Y$ dan $X_{1}, X_{2}, \ldots, X_{k}$, persamaan regresi ditulis berdasarkan difference (beda umum), $Y_{t}^{\prime}=Y_{t}-Y_{t-1}$ dan $X_{t 1}^{\prime}=X_{t 1}-$ $X_{t-1,1}, X_{t 2}^{\prime}=X_{t 2}-X_{t-1,2}$, dan seterusnya. Difference disarankan ketika nilai Durbin-Watson berasosiasi dengan regresinya termasuk variabel biasa yang nilainya mendekati 0 .

Satu alasan digunakan difference yaitu berdasarkan argumen berikut. Misalkan saja Persamaan (1) dan (2) sebagai berikut 


$$
Y_{t}=\beta_{0}+\beta_{1} X_{t}+\ldots+\beta_{k} X_{t, k}+e_{t}
$$

Dengan

$$
e_{t}=\rho e_{t-1}+\mu_{t}
$$

Persamaan (2) merupakan bentuk yang paling sering dipakai untuk menyatakan autokorelasi sederhana dan sering disebut proses autoregresi AR(1), dimana

$$
\begin{aligned}
& \rho=\text { korelasi antara eror yang berturutan } \\
& \mu_{t}=\text { error random } \sim N\left(0, \sigma^{2}\right) \\
& e_{t}=\mu_{t} \text { ketika } \rho=0
\end{aligned}
$$

Sehingga model untuk suatu periode waktu yaitu

$$
Y_{t-1}=\beta_{0}+\beta_{1} X_{t-1}+\beta_{k} X_{t-1, k}+e_{t-1}
$$

Dengan mengalikan kedua ruas Persamaan (3) dengan $\rho$ dan mengurangkan dengan Persamaan (1) hasilnya,

$$
Y_{t}-\rho Y_{t-1}=\beta_{0}-\rho \beta_{0}+\left(\beta_{1} X_{t}-\rho \beta_{1} X_{t-1}\right)+\left(\beta_{k} X_{t, k}-\rho \beta_{k} X_{t-1, k}\right)+\left(e_{t}-\rho e_{t-1}\right)
$$

atau

$$
Y_{t}^{\prime}=\beta_{0}^{\prime}+\beta_{1} X_{t}^{\prime}+\beta_{k} X_{t k}^{\prime}+\mu_{t}
$$

dimana persamaan mengindikasikan suatu difference secara umum

$$
\begin{aligned}
& \beta_{0}^{\prime}=\beta_{0}(1-\rho) \\
& Y_{t}^{\prime}=Y_{t}-\rho Y_{t-1} \\
& X_{t, k}^{\prime}=X_{t, k}-\rho X_{\mathrm{t}-1, \mathrm{k}} k=1,2, . ., n
\end{aligned}
$$

Model pada Persamaan (4) memiliki error $\mu_{t}$ yang berdistribusi secara independen dengan rata-rata 0 dan variansi konstan. Maka metode regresi secara umum dapat diterapkan pada model ini.

Jika korelasi antara error yang berturutan kuat ( $\rho$ dekat 1) difference sederhana dapat digunakan

$$
\begin{aligned}
& Y_{t}^{\prime}=Y_{t}-Y_{t-1} \\
& X_{t, k}^{\prime}=X_{(t, k)}-X_{(t-1, k)}
\end{aligned}
$$

dengan

$k=$ banyaknya variabel bebas yang digunakan.

$\beta_{0}^{\prime}=$ koefisien setelah dilakukan difference

$Y_{t}^{\prime}=$ variabel terikat dalam difference

$X_{t}^{\prime}=$ variabel bebas dalam difference

\section{Statistik Durbin Watson}

Uji ini dikemukakan oleh statistikawan J. Durbin dan G.S. Watson[3], Sehingga uji ini dikenal dengan nama Uji Durbin-Watson. Uji ini hanya cocok untuk pola regresi order pertama yang mengambil bentuk:

$$
e_{t}=\rho e_{t-1}+\mu_{t}
$$

Uji Durbin Watson sendiri dirumuskan sebagai berikut : 


$$
d=\frac{\sum_{t=2}^{n}\left(e_{t}-e_{t-1}\right)^{2}}{\sum_{t=1}^{n} e_{t}^{2}}
$$

Kebaikan dari statistik uji $d$ Durbin Watson ini sendiri adalah bahwa perhitungan didasarkan atas $e_{t}$, perkiraan residual pengganggu $e_{t}$ yang secara rutin dihitung di dalam analisis regresi. Karena $\sum e_{t}^{2}$ dan $\sum e_{t-1}^{2}$ hanya berbeda satu pengamatan, maka keduanya dapat dianggap sama. Sehingga $\sum e_{t}^{2}=\sum e_{t-1}^{2}$, maka Persamaan 2.2 dapat ditulis kembali sebagai berikut

$$
d \sim 2\left[1-\frac{\sum e_{t} e_{t-1}}{\sum e_{t}^{2}}\right]
$$

Koefisien korelasi dapat ditentukan dengan persamaan :

$$
\hat{\rho}=\frac{\sum e_{t} e_{t-1}}{\sum e_{t}^{2}}
$$

Sebagai penduga dari koefisien autokorelasi tingkat satu ( $\rho$ ), yang nilainya berada pada $-1<\rho<1$, maka dengan menggunakan Persamaan (10) bentuk persamaan dapat dinyatakan sebagai berikut

$$
d \sim 2(1-\rho)
$$

Ini berarti bila $\rho$ mendekati 0 yang menunjukkan tidak adanya autokorelasi, $d$ akan mendekati 2. Demikian pula bila $\rho$ mendekti 1 , yang menunjukan ada autokorelasi serial positif, $d$ akan mendekati 0 , dan bila $\rho$ mendekati -1, ini menunjukkan ada korelasi serial negatif, $d$ akan mendekati 4 .

\section{Hasil dan Pembahasan}

Suatu model regresi dikatakan baik ketika memenuhi uji asumsi klasik yang terdiri dari uji normalitas, uji autokorelasi, uji Multikolinearitas, dan uji Heteroskedastisitas. Model regresi sederhana pada paper ini tidak digunakan karena tidak lulus dalam uji asumsi klasik khususnya pada uji Autokorelasi, sehingga harus dilakukan transformasi data, dalam paper ini dilakukan difference data untuk mentransformasikan data sehingga data dapat memenuhi uji asumsi klasik, pada modelnya terdapat perbedaan dengan model regresi dengan data yang tidak dilakukan difference. Uji $\mathrm{F}$, uji t, dan koefisien determinasi juga harus dilakukan untuk melihat adakah pengaruh variabel bebas terhadap harga saham dan seberapa besar pengaruhnya . Berikut merupakan model dengan difference masing-masing bank.

\subsection{Bank BCA dengan Difference}


Nilai Durbin Watson atau $d$ kecil yaitu $d=0.3559$ maka terdapat korelasi yang sangat kuat antar residualnya maka dapat asumsikan bahwa $\rho=$ 1, sehingga persamaan regresinya dari data lampiran difference BBCA menjadi: $Y_{t}^{\prime}=1.6905 X_{t, 1}^{\prime}-70.1408 X_{t, 2}^{\prime}+544.8455 X_{t, 3}^{\prime}+0.1846 X_{t, 4}^{\prime}$

Dengan

$$
\begin{aligned}
& \beta_{0}^{\prime}=\beta_{0}(1-1)=0 \\
& Y_{t}^{\prime}=Y_{t}-Y_{t-1} \\
& X_{t, k}^{\prime}=X_{t, k}-X_{t-1, k} k: 1,2,3,4
\end{aligned}
$$

Maka diperoleh persamaan regresi difference seperti berikut untuk BBCA

$$
Y_{t}=1.6905 X_{t, 1}^{\prime}-70.1408 X_{t, 2}^{\prime}+544.8455 X_{t, 3}^{\prime}+0.1846 X_{t, 4}^{\prime}+Y_{t-1}
$$

\subsection{Bank BRI dengan Difference}

Nilai Durbin Watson atau $d$ cukup besar yaitu $d=0.9319$ maka terdapat korelasi yang tidak teralu kuat antar residualnya maka dapat diestimasikan bahwa nilai $\rho \approx 1-\frac{d}{2}=1-\frac{0.9319}{2}=0.534$, sehingga persamaan regresinya dari data lampiran difference Bank BRI dengan nilai estimasi $\rho=$ 0.534 maka persamaannya menjadi :

$$
Y_{t}^{\prime}=-1739+2.002 X_{t, 1}^{\prime}-52.36 X_{t, 2}^{\prime}+85 X_{t, 3}^{\prime}+0.224 X_{t, 4}^{\prime}
$$

Dengan

$$
\begin{aligned}
& \beta_{0}^{\prime}=\beta_{0}(1-0.534)=-1739 \\
& Y_{t}^{\prime}=Y_{t}-0.534 Y_{t-1} \\
& X_{t, k}^{\prime}=X_{t, k}-0.534 X_{t-1, k} k: 1,2,3,4
\end{aligned}
$$

Maka diperoleh persamaan regresi difference seperti berikut untuk BBRI

$$
Y_{t}=-1739+2.002 X_{t, 1}^{\prime}-52.36 X_{t, 2}^{\prime}+85 X_{t, 3}^{\prime}+0.224 X_{t, 4}^{\prime}+0.534 Y_{t-1}
$$

\subsection{Bank BNI dengan Difference}

Nilai Durbin Watson atau $d$ kecil yaitu $d=0.3184$, maka terdapat korelasi yang sangat kuat antar residualnya maka dapat asumsikan bahwa $\rho=$ 1, sehingga persamaan regresinya dari data lampiran difference Bank BNI menjadi:

$$
Y_{t}^{\prime}=1.16473 X_{t, 1}^{\prime}-10.84073 X_{t, 2}^{\prime}+97.30165 X_{t, 3}^{\prime}-0.05161 X_{t, 4}^{\prime}
$$

Dengan

$$
\begin{aligned}
& \beta_{0}^{\prime}=\beta_{0}(1-1)=0 \\
& Y_{t}^{\prime}=Y_{t}-Y_{t-1} \\
& X_{t, k}^{\prime}=X_{t, k}-X_{t-1, k} k: 1,2,3,4
\end{aligned}
$$

Maka diperoleh persamaan regresi dengan difference seperti berikut untuk Bank BNI

$$
Y_{t}=1.16473 X_{t, 1}^{\prime}-10.84073 X_{t, 2}^{\prime}+97.30165 X_{t, 3}^{\prime}-0.05161 X_{t, 4}^{\prime}+Y_{t-1}
$$

\subsection{Bank Mandiri dengan Difference}


Nilai Durbin Watson atau $d$ kecil yaitu $d=0.4606$, maka terdapat korelasi yang sangat kuat antar residualnya maka dapat asumsikan bahwa $\rho=$ 1, sehingga persamaan regresinya dari data lampiran difference Bank BNI menjadi:

$$
Y_{t}^{\prime}=2.3272 X_{t, 1}^{\prime}-73.5994 X_{t, 2}^{\prime}+397.7427 X_{t, 3}^{\prime}+0.1823 X_{t, 4}^{\prime}
$$

Dengan

$$
\begin{aligned}
& \beta_{0}^{\prime}=\beta_{0}(1-1)=0 \\
& Y_{t}^{\prime}=Y_{t}-Y_{t-1} \\
& X_{t, k}^{\prime}=X_{t, k}-X_{t-1, k} k: 1,2,3,4
\end{aligned}
$$

maka diperoleh persamaan regresi dengan difference seperti berikut untuk Bank Mandiri :

$$
Y_{t}=2.3272 X_{t, 1}^{\prime}-73.5994 X_{t, 2}^{\prime}+397.7427 X_{t, 3}^{\prime}+0.1823 X_{t, 4}^{\prime}+Y_{t-1}
$$

\subsection{Bank CIMB Niaga dengan Difference}

Nilai Durbin Watson atau $d$ Dari Tabel 4.11 nilai $d$ kecil yaitu $d=0.3158$, maka terdapat korelasi yang sangat kuat antar residualnya maka dapat asumsikan bahwa $\rho=1$, sehingga persamaan regresinya dari data lampiran difference Bank CIMB Niaga menjadi

Dengan

$$
Y_{t}^{\prime}=0.4191 X_{t, 1}^{\prime}+68.59 X_{t, 2}^{\prime}-105 X_{t, 3}^{\prime}-0.00699 X_{t, 4}^{\prime}
$$

$$
\begin{aligned}
& \beta_{0}^{\prime}=\beta_{0}(1-1)=0 \\
& Y_{t}^{\prime}=Y_{t}-Y_{t-1} \\
& X_{t, k}^{\prime}=X_{t, k}-X_{t-1, k} k: 1,2,3,4
\end{aligned}
$$

Maka diperoleh persamaan regresi dengan difference seperti berikut untuk Bank CIMB Niaga: $Y_{t}=0.4191 X_{t, 1}^{\prime}+68.59 X_{t, 2}^{\prime}-105 X_{t, 3}^{\prime}-0.00699 X_{t, 4}^{\prime}+Y_{t-1}$

Model saham yang dibentuk (setelah difference) oleh masing-masing bank telah lulus uji asumsi klasik di mana model tidak mengalami autokorelasi, tidak ada Multikolinearitas, sebaran residualnya normal, dan tidak ada gejala Heteroskedastisitas, maka model-model bank tersebut layak untuk dipakai. Untuk nilai MAPE (Mean Absolute Percentage Error) yang paling kecil adalah saham bank mandiri sebesar $4.82 \%$.

\subsection{Interpretasi Model}

Dengan menggunakan metode MAPE maka persamaan regresi dengan difference yang paling baik adalah model regresi saham Bank Mandiri dengan rataan error sebesar $4.822 \%$. Modelnya sebagai berikut:

$$
Y_{t}=2.3272 X_{t, 1}^{\prime}-73.5994 X_{t, 2}^{\prime}+397.7427 X_{t, 3}^{\prime}+0.1823 X_{t, 4}^{\prime}+Y_{t-1}
$$

- $\quad Y_{t}$ merupakan Saham Bank Mandiri pada waktu t. 
- 2.3272X $X_{t, 1}^{\prime}$ menunjukkan IHSG mempengaruh sebesar 2.3272 point saham Bank Mandiri untuk setiap peningkatan IHSG sebanyak satu point di BEI.

- $\quad-73.5994 X_{t, 2}^{\prime}$ menunjukkan Inflasi menunjukkan pengaruh yang berlawanan sebesar 73.5994 point ketika inflasi naik 1\% pada penerbitan inflasi oleh Bank Indonesia.

- 397.7427X $X_{t, 3}^{\prime}$ menunjukkan BI rate memberikan pengaruh sebesar 397.7427 point pada saham Bank Mandiri untuk setiap peningkatan nilai BI rate sebesar $1 \%$.

- $\quad 0.1823 X_{t, 4}^{\prime}$ menunjukkan nilai tukar rupiah terhadap dolar memberikan pengaruh sebesar 0.1823 point pada saham Bank Mandiri untuk setiap kenaikan nilai kurs rupiah sebesar 1 point.

- $\quad Y_{t-1}$ adalah harga saham Bank Mandiri pada periode waktu sebelumnya.

\section{Simpulan}

Berdasarkan uraian dan perhitungan yang dilakukan pada bab sebelumnya dapat diambil simpulan sebagai berikut:

1. Pengaruh dari IHSG, inflasi, BI rate dan nilai tukar rupiah terhadap harga saham berdasarkan uji $\mathrm{F}$ memiliki pengaruh yang signifkan namun dalam pengaruh secara parsialnya, masing model dipengaruhi secara signifikan oleh variabel $X_{1}, X_{2}, X_{3}$ dan $X_{4}$ yang berbeda.

2. Pada pemodelan saham dapat digunakan metode regresi linear berganda namun, harus diperhatikan bahwa pentingnya dilakukan uji asumsi klasik agar mendapatkan model regresi yang memiliki sifat BLUE. Data saham merupakan data runtun waktu sehingga memiliki perlakuan yang berbeda dengan regresi linear yang umumnya ada. Maka data saham yang dimodelkan secara regresi linear berganda persamaannya dapat dibentuk berdasarkan waktu.

3. Model saham yang mempunyai model terbaik dilihat dari ukuran error (MAPE) sebesar 4.822\% adalah saham Bank Mandiri selama periode 5,5 tahun kebelakang.

Modelnya:

$$
Y_{t}=2.3272 X_{t, 1}^{\prime}-73.5994 X_{t, 2}^{\prime}+397.7427 X_{t, 3}^{\prime}+0.1823 X_{t, 4}^{\prime}+Y_{t-1}
$$

\section{Daftar Pustaka}

1. Darmadji, Tjipto dan Hendry M.F., 2001. Pasar Modal di Indonesia, Salemba Emapat, Jakarta.

2. Rahayu, Siti. 2009. Penggunaan Metode Durbin Watson Dalam Menyelesaikan Model Regresi yang Mengandung Autokorelasi. Skripsi. Program S1 Universitas Sumatra Utara. Medan

3. Sembiring,R.K. 2003. ”Analisis Regresi”. Edisi Kedua. ITB 
4. Sunariyah, 2003. Pengantar Pengetahuan Pasar Modal, edisi ke tiga, UPP-AMP YKPN, Yogyakarta. 
Yeremia et al/ JMI Vol. 9 No 1, April 2013, pp 19-27 